\title{
W. Mike Edmunds and Paul Shand (eds): Natural groundwater quality
}

\author{
Blackwell, 2008, 168 figs, 70 tables, 469 pp, ISBN 978-14051-5675-2
}

\author{
Natascha Wahlberg Macías
}

Published online: 11 November 2010

(C) Springer-Verlag 2010

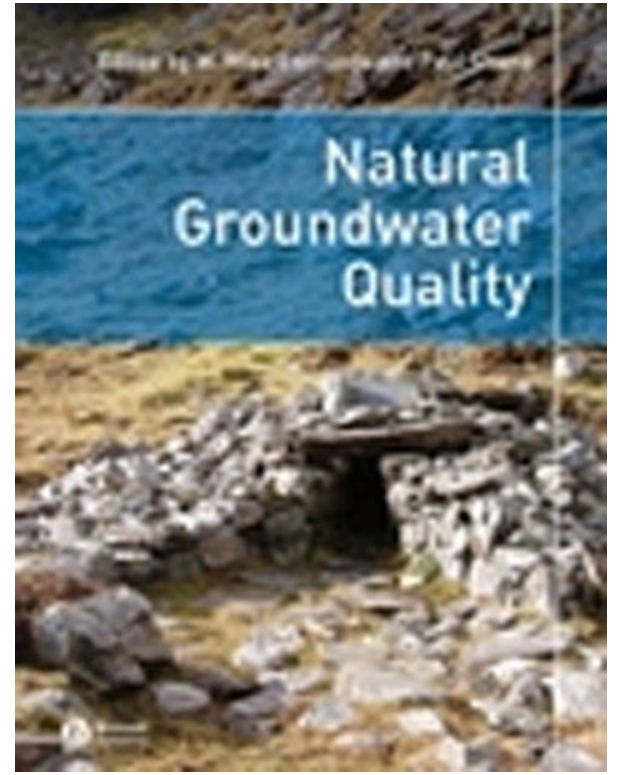

This book is a series of important studies executed by a consortium of European scientists. Focus is on establishing natural baseline quality of groundwater systems in Europe as the basis for understanding geochemical processes in aquifers and providing a framework for defining what constitutes pollution.

The text is organized into 22 studies and an index. The first study is written by Edmunds and Shand and is an introduction explaining how to define and quantify groundwater baseline using hydrogeochemical controls, and the timescales of groundwater movement and other spatial considerations. The second study is written by the same authors and documents the inorganic chemistry baseline of European groundwater systems, exposing widely all the inorganic substances typically found in the different European groundwater systems and summarizing for each country.

In other studies, Gooddy and Hinsby use total organic carbon (TOC) and dissolved organic carbon (DOC) to establish the organic carbon baseline; Postma and others use geochemical modeling to obtain information about the flow, confined and unconfined zones of aquifers, and water age; Purtschert uses environmental tracers to study the groundwater residence times; Van Camp and Walraevens discuss identifying and interpreting baseline trends; and de Melo et al. review monitoring systems, parameter selection, measurement, and recommended sampling frequency.

This book is a well-written explanation of the natural groundwater quality of European aquifers. These studies will serve as a good reference for researchers, agencies, and professional organizations in carrying out the European Groundwater Directive and for researching other European aquifers that have not been well documented. The book also points out the importance of having a more coordinated groundwater management program in Europe.

N. W. Macías $(\bowtie)$

University of Malaga, Malaga, Spain

e-mail: nwmacias@hotmail.com 